\title{
РАСЧЕТ ЧАСТОТНЫХ И ЭНЕРГЕТИЧЕСКИХ ХАРАКТЕРИСТИК СОСТАВНОГО МЕТАЛЛО-ДИЭЛЕКТРИЧЕСКОГО РЕЗОНАТОРА МЕТОДОМ ЧАСТИЧНЫХ ОБЛАСТЕЙ
}

\author{
САВИН К. Г., ГОЛУБЕВА И. П., ПРОКОПЕНКО Ю. В. \\ Национальный технический университет Украины \\ «Киевский политехнический институт», \\ Украина, Киев, 03056, пр-т Победь 37
}

\begin{abstract}
Аннотация. Предложен новый метод расчета частотных и энергетических характеристик различных типов колебаний металло-диэлектрического резонатора СВЧ. Представлены результаты измерений экспериментального образца резонатора, которые хорошо согласуются с расчетными. С помощью метода частичных областей получены зависимости частотных и энергетических характеристик резонатора от его геометрических и электрофизических параметров. Обнаружена высокая чувствительность резонансной частоты основного типа колебаний на толщину воздушной неоднородности. При этом внедрение неоднородности повышает добротность резонатора. Таким образом, представленная конструкция может быть использована в качестве высокодобротного перестраиваемого резонатора
\end{abstract}

Ключевые слова: перестраиваемый резонатор; микроэлектромеханическая перестройка; задача на собственные колебания; высокочувствительная перестройка частоты

\section{ВВЕДЕНИЕ}

Прогресс беспроводных технологий за последние годы вызвал интерес к перестраиваемым селективным устройствам. Диэлектрические резонаторы (ДР) используются в качестве основного элемента селективных устройств благодаря высокой добротности и малым размерам. Электромеханическая перестройка резонансной частоты выгодно отличается сохранением высокой добротности [1]. Использование составных ДР позволяет получить перестройку резонансной частоты до $30 \%$ при перемещении составных частей на десятки-сотни микрометров в сантиметровом диапазоне длин волн [2].

Металло-диэлектрические резонаторы (МДР) имеют меньшие частоты низших типов колебаний и больший диапазон пере- стройки по сравнению с ДР аналогичных размеров. Применение составных МДР (СМДР) позволяет уменьшить габариты селективных устройств и увеличить их диапазон перестройки.

Применение СМДР требует решения задачи о собственных колебаниях для расчета резонансных частот. В данной работе рассмотрено решение этой задачи методом частичных областей (МЧО).

\section{РЕШЕНИЕ ЗАДАЧИ НА СОБСТВЕННЫЕ КОЛЕБАНИЯ}

Предлагаемая модель СМДР представлена на рис. 1, которая включает две соосные цилиндрические области радиуса $R$, высотами $h$ и $d$, с относительными проницаемостями $\varepsilon_{1}$ и $\varepsilon_{2}$, помещенные между двумя металлическими 